\title{
Road Surface State Recognition Based on SVM Optimization and Image Segmentation Processing
}

\author{
Jiandong Zhao, ${ }^{1}$ Hongqiang $\mathrm{Wu},{ }^{1}$ and Liangliang Chen ${ }^{2}$ \\ ${ }^{1}$ School of Mechanical and Electronic Control Engineering, Beijing Jiaotong University, Beijing 100044, China \\ ${ }^{2}$ National Engineering Laboratory for Surface Transportation Weather Impacts Prevention, \\ Broadvision Engineering Consultants, Kunming 650041, China
}

Correspondence should be addressed to Jiandong Zhao; zhaojd@bjtu.edu.cn

Received 3 April 2017; Accepted 1 June 2017; Published 6 July 2017

Academic Editor: Xiaoming Chen

Copyright (C) 2017 Jiandong Zhao et al. This is an open access article distributed under the Creative Commons Attribution License, which permits unrestricted use, distribution, and reproduction in any medium, provided the original work is properly cited.

\begin{abstract}
Adverse road condition is the main cause of traffic accidents. Road surface condition recognition based on video image has become a central issue. However, hybrid road surface and road surface under different lighting environments are two crucial problems. In this paper, the road surface states are categorized into 5 types including dry, wet, snow, ice, and water. Then, according to the original image size, images are segmented; 9-dimensional color eigenvectors and 4 texture eigenvectors are extracted to construct road surface state characteristics database. Next, a recognition method of road surface state based on SVM (Support Vector Machine) is proposed. In order to improve the recognition accuracy and the universality, a grid searching algorithm and PSO (Particle Swarm Optimization) algorithm are used to optimize the kernel function factor and penalty factor of SVM. Finally, a large number of actual road surface images in different environments are tested. The results show that the method based on SVM and image segmentation is feasible. The accuracy of PSO algorithm is more than $90 \%$, which effectively solves the problem of road surface state recognition under the condition of hybrid or different video scenes.
\end{abstract}

\section{Introduction}

According to statistics, $16.12 \%$ of traffic accidents on the highway are ascribed to slippery road conditions [1] since 2007 in China. By analysis of accidents' characteristics, it can be concluded that the traffic accident rate increases under the water, snow, ice, and freezing road surface conditions and that road surface conditions greatly affect the highway traffic safety and transport efficiency. Therefore, it is urgent to carry out research on the road surface state recognition and provide reference and theoretical basis for traffic control and meteorological management to ensure traffic safety [2].

In the field of traffic meteorology, the road surface state can be categorized in dry, wet, water, snow, and ice types according to different forms of liquid on road surface. At present, the road surface detection sensor is the main entrance to obtain the information of road surface slippery conditions. Cai et al. [3] used underground embedded road surface condition detector to realize the recognition. Gailius and Jacenas [4] collected the frictional noise between the tire and the road surface and obtained the road surface characteristics based on the noise spectrum analysis method. Qi et al. [5] extracted road surface characteristics and anti-holdprocess parameters, according to the principle of maximum proximity to identify the state of the road surface. Alonso et al. [6] proposed a real-time acoustics road surface state recognition system based on tire-road noise and used the noise measurement system and the signal processing algorithm for road surface state classification, and finally, precise classification of dry and wet road state was realized. Wang et al. [7] proposed D-S evidence theory and artificial neural network method for recognition and prediction of traffic state level under adverse weather conditions. However, the road surface sensor can only obtain the information of the section and the maintenance is extremely inconvenient; hence the actual effect is not ideal.

With the widespread application of road surveillance cameras, more and more scholars pay attention to the image processing technology of road surface slippery condition recognition. Andreas and Wilco [8] extracted the gray scale 
feature of road surface image and designed the neural network classifier for road surface state recognition. Anis et al. [9] analyzed the set and spectrum of road surface reflection image and described the correlation between the surface texture and the friction coefficient, by which the reflection image of designated location can be monitored and identified. Chen [10] extracted low-order statistical features of road surface images including gray level cooccurrence matrix texture feature parameters and used linear discriminant function to determine the road surface state. Ueda et al. [11] and Yoda et al. [12] measured and analyzed the road surface roughness, the proportion of low-frequency reflection signal components and high-frequency components, and the average reflection intensity to determine the state of the road surface based on CCD camera technology. Yamamoto et al. [13] applied the human-computer interaction method to extract the gray scale value and temperature characteristics parameters of the road surface for the road surface state prediction, and measurement accuracy was tested to be more than $80 \%$. Muneo et al. [14] used vehicle camera to collect traffic information; the parameters of road surface image polarization characteristics were utilized to establish the road slippery condition evaluation model. Becchi et al. [15] obtained the water condition video of the road surface; the rain density judge values and image analysis results were combined to evaluate the depth of water film on the road surface, by which the road condition evolution pattern can be forecasted. Fukui et al. [16] analyzed the slippery condition of the road by calculating the brightness and spatial spectrum of road surface images. Li et al. [17] extracted RGB, HIS, and YUV of road surface images and established the road surface state recognition model based on improved BP neural network. The recognition accuracy rate of this model could reach more than $85 \%$. However, it was still on the theoretical research stage with the small size of training sample. Liu and Huang [18] collected wet road images and then designed a SVM classifier of road slippery state classification. Among them, the misjudgment rate of the dry state is slightly high, while the recognition accuracy of snow state is slightly high. Besides, the identification of hybrid road surface state was still to be studied. Wan et al. [19] used the RBF neural network model to discriminate the slippery conditions of different roads, and the recognition accuracy was $78.4 \%$. Among them, the recognition accuracy of dry and silt state is low, and the recognition accuracy of snow and ice state is high.

Image feature extraction is a key step in image recognition. Zhang et al. [20] extracted the eigenvector of RGB color moment and the Munsell color moment from the images. The results show that the color moment feature can describe the color characteristic of the image well. Shinde et al. [21] extracted a variety of color features of images to form a preprocessing database of color eigenvector and then used machine learning to perform image classification experiments. The experimental results show that the classification accuracy can be achieved based on multiple color feature databases. Bhave et al. [22] extracted the color feature by calculating the average value of each color component and then used gray level cooccurrence matrix to extract texture eigenvectors. Based on the feature values above, image state can be classified. Haralick et al. [23] proposed some easy-to-calculate texture eigenvectors based on the gray level cooccurrence matrix. The texture feature is used to identify the aerial images. Experimental results show that the texture feature is the applicability of image classification. Mohanaiah et al. [24] extracted the four image texture eigenvectors based on the gray level cooccurrence matrix, including the second moment, correlation, inverse moment, and entropy. The recognition experiments show that calculation time can be saved and the recognition accuracy is high via these texture features.

Reviewing the above literatures, it is found that the existing problems and development trends of image recognition technology are as follows:

(1) Image recognition technology is the main technology of road surface recognition. However, due to the complexity of the road scene and the weak adaptability of the vision system to the illumination change, the road condition detection method based on machine vision has the problem of weak adaptability, the poor robustness of illumination, and low recognition accuracy at present.

(2) The identification of the hybrid road surface state is one of the main problems in this study.

(3) Using SVM, neural network, and other machine learning methods to identify the road surface state is the development trend.

(4) Extracting appropriate multidimensional color and texture eigenvectors can help to improve the accuracy of road surface state recognition.

Therefore, this paper presents a new method based on SVM classifier and image segmentation processing to solve the problem of the small size of the sample and nonlinear and high-dimension pattern recognition. First of all, the comprehensive sample database of road surface state is established by collecting road surface images in different scenes through a variety of ways. Then, 13-dimensional color and texture eigenvectors are extracted to build the training database of road surface state. Next, the optimal parameters of the SVM classifier are trained by the grid searching optimization algorithm and the PSO algorithm, respectively. Thus two kinds of road surface state classification models are built and the performances of the two optimization classification models are compared. For the hybrid road surface state recognition, the road surface state image is segmented into blocks and the overall state of road surface state is presented. Finally, the algorithm proposed is tested and the ideal recognition results are obtained based on the large-scale samples.

\section{Eigenvectors Extraction of Road Surface State from Images}

The road surface image information mainly includes color, texture, shape, and other characteristics. In this paper, representatively typical road surface state image samples are 
selected and color and texture eigenvectors are extracted, and the road surface state image feature database can be formed by researching color and the texture characteristics of road state.

2.1. Extraction of Color Eigenvectors. Color eigenvectors of road surface image are usually stable and not sensitive to size or direction. Among them, the color moment feature has the characteristics of translation invariance, rotation invariance, and scale invariance, which can ensure the integrity of image color information $[20,21,25]$. Therefore, this paper adopts the third-order color moment method to extract the road surface image color feature. The definitions are as follows:

$$
\begin{aligned}
\mu_{i} & =\frac{1}{N} \sum_{j=1}^{N} p_{i, j}, \\
\sigma_{i} & =\left\{\frac{1}{N} \sum_{j=1}^{N}\left(p_{i, j}-\mu_{i}\right)^{2}\right\}^{1 / 2}, \\
s_{i} & =\left\{\frac{1}{N} \sum_{j=1}^{N}\left(p_{i, j}-\mu_{i}\right)^{3}\right\}^{1 / 3},
\end{aligned}
$$

where $i$ is the color channel and $j$ is the gray value of image. $\mu_{i}$ is the first-order color moment of image $i . \sigma_{i}$ is the secondorder color moment. $s_{i}$ is the third-order color moment. $p$ is the probability of the pixels with gray scale $j$ occurrences in the $i$ th color channel of image. $N$ is the total number of pixels in the image. Equation (2) is a 9-dimensional color moment vector, indicating the color feature of images, based on the HSV (hue, saturation, and brightness) color model:

$$
F_{\text {color }}=\left[\mu_{H}, \sigma_{H}, s_{H}, \mu_{S}, \sigma_{S}, s_{S}, \mu_{V}, \sigma_{V}, s_{V}\right] .
$$

2.2. Extraction of Texture Eigenvectors. Gray level cooccurrence matrix can better represent the texture information $[23,26,27]$. In this paper, we choose the gray level cooccurrence matrix method to extract four commonly used texture features of road surface images.

(1) Energy

$$
\mathrm{ASM}=\sum_{i} \sum_{j} q(i, j \mid d, \theta)^{2}
$$

Energy reflects the texture thickness of image. When the texture is coarse relatively, ASM is larger; on the contrary, ASM is smaller, where $i, j$ are gray scale values of pixels. $d$ is the spatial relationship between the two pixels. $\theta$ is the generated direction of the gray level cooccurrence matrix. $q$ is the number of occurrences of $i$ and $j$ pixels with the spatial relationship $d$.

\section{(2) Entropy}

$$
\mathrm{ENT}=-\sum_{i} \sum_{j} q(i, j \mid d, \theta) \log _{2} q(i, j \mid d, \theta) .
$$

Entropy reflects the amount of the image information. When the image has more textures, the entropy value is larger. If the image contains fewer textures, the entropy value is smaller. If the image has no textures, the entropy value is close to zero.

(3) Contrast

$$
\mathrm{CON}=\sum_{i} \sum_{j}(i-j)^{2} q(i, j \mid d, \theta) .
$$

The contrast reflects the clarity of the image texture. In images, the deeper the texture groove, the greater the contrast, and the clearer the image texture visual effect.

(4) Correlation

$$
\operatorname{COR}=\sum_{i} \sum_{j} \frac{(i j) q(i, j)-\lambda_{1} \lambda_{2}}{\varepsilon_{1} \varepsilon_{2}},
$$

where $\lambda_{1}=\sum_{i} \sum_{j} i \cdot q(i, j), \lambda_{2}=\sum_{i} \sum_{j} j \cdot q(i, j), \varepsilon_{1}^{2}=$ $\sum_{i} \sum_{i} q(i, j)\left(i-\lambda_{1}\right)^{2}$, and $\varepsilon_{2}^{2}=\sum_{i} \sum_{i} q(i, j)\left(i-\lambda_{2}\right)^{2}$.

Correlation value reflects the correlation of local gray scale in images. When the values of the matrix elements are evenly equal, the correlation value is large. On the contrary, when the values of the matrix elements are very different, the correlation value is small.

Based on the research above, a set of 13-dimensional road surface state eigenvectors is determined as

$$
\begin{aligned}
& \text { feature }=\left[\mu_{H}, \sigma_{H}, s_{H}, \mu_{S}, \sigma_{S}, s_{S}, \mu_{V}, \sigma_{V}, s_{V},\right. \text { ASM, ENT, } \\
& \text { CON, COR }] .
\end{aligned}
$$

\section{Database Construction of Road Surface State Feature}

3.1. Image Samples Collection of Road Surface State. As shown in Figure 1, we set up a road surface image acquisition experimental system including the road surface image acquisition camera, the hard disk video recorder, and the computer. This system can cover the entire road and achieve all-weather road image acquisition.

The basis of road surface state recognition is to establish the road surface state feature database, which needs to collect a large number of road surface state image samples through various ways. Because of the simplicity of the road surface images collected by the experimental system, we also use the highway video surveillance resources, network resources, and other video resources to collect road images to expand the sample database.

3.2. Image Samples Database Construction of Road Surface State. The road surface state is divided into five types including dry, wet, water, ice, and snow. According to the influence of original images to samples database under the condition of different images size and lighting scenes, the original image segmentation principle is proposed as shown in Table 1. According to Table 1, original images are divided into blocks, 



FIGURE 1: Road surface images acquisition system.

TABLE 1: Image segmentation principle.

\begin{tabular}{lc}
\hline Size of images $(\mathrm{px})$ & Size of blocks $(\mathrm{px})$ \\
\hline $100000 \leq$ image $<1000000$ & $80 \times 80$ \\
$1000000 \leq$ image $<2000000$ & $100 \times 100$ \\
$2000000 \leq$ image $<3000000$ & $200 \times 200$ \\
$3000000 \leq$ image $<5000000$ & $300 \times 300$ \\
$5000000 \leq$ image $<8500000$ & $500 \times 500$ \\
\hline
\end{tabular}

and then the single state blocks are selected to construct the road surface state samples, which effectively guarantee the quality and purity of the road surface image database.

In this paper, 500 dry images, 500 wet images, 500 water images, 500 snow images, and 500 ice images totaling 2500 images were collected to construct the sample database. Some of the image samples are shown in Figure 2.

\subsection{Database Construction of Road Surface State Feature.} Based on the road surface state image sample database, 500 samples were collected for each state, and the color and texture eigenvectors were extracted to build the road surface state feature database. Figures 3-6 show part of the color and texture feature curves of 200 samples for each state.

As shown in Figure 3, the range of $V$ first-order moment of dry samples is $[0.31,0.93]$, the range of $V$ first-order moment of the wet samples is $[0.48,0.73]$, the range of $V$ firstorder moment of water samples is $[0.47,0.88]$, the range of $V$ first-order moment of snow samples is [0.71, 0.94], and the range of $V$ first-order moment of ice samples is [0.41,0.93]. It can be seen that there is a large difference in first-order moment values between dry samples and snow samples, while the first-order moment curves of the wet, water, and ice samples show characteristics of overlapping.

As shown in Figure 4, the range of $V$ second-order moment of dry samples is [0.03, 0.21], the range of $V$ secondorder moment of wet samples is $[0.04,0.20]$, the range of $V$ second-order moment of water samples is $[0.01,0.25]$, the range of $V$ second-order moment of snow samples is [0.01, $0.07]$, and the range of second moment of ice samples is [0.04, $0.16]$. It can be seen that the $V$ second moment values of snow samples are small, and there is a big difference with the other four samples. The $V$ second moment curves of dry, wet, water, and ice samples are hard to distinguish because of obvious overlapping.

As shown in Figure 5, the range of energy values of the dry samples is $[1.52,4.74]$, the range of energy values of the wet samples is $[1.71,4.92]$, the range of energy values of the water samples is $[0.18,2.48]$, the range of energy values of the snow samples is $[0.01,2.13]$, and the range of energy values of ice samples is $[1.86,4.94]$. It can be seen that the energy value curves of water and snow samples are overlapped, while the curves of energy values for dry, wet, and ice samples show characteristics of overlap.

As shown in Figure 6, the range of entropy of dry samples is $[0.01,0.35]$, the entropy of wet samples is $[0.01,0.36]$, the range of entropy of water samples is $[0.04,0.98]$, the range of entropy of snow samples is [0.14, 0.99], and the range of entropy of the ice samples is $[0.03,0.25]$. It can be seen that the entropy curves of wet and ice samples are overlapped, and the entropy curves of dry, water, and snow samples are overlapped.

It can be concluded that the single feature curves of the five states have an overlapping area, but there are obvious differences in the feature vectors between at least two kinds of states. The 13-dimensional feature mentioned in this paper can help to accurately identify the road surface state.

\section{Design of SVM Classification Optimization}

4.1. Design of Classifier Based on SVM. The principle of SVM $[28,29]$ is to find the optimal hyperplane, which ensures the accuracy of the hyperplane classification, while the distance on both sides of the hyperplane can be maximized. A nonlinear multiclass SVM classifier is designed for the recognition of hybrid road surface states. The nonlinear-to-linear 




FIGURE 2: Road surface image sample library.

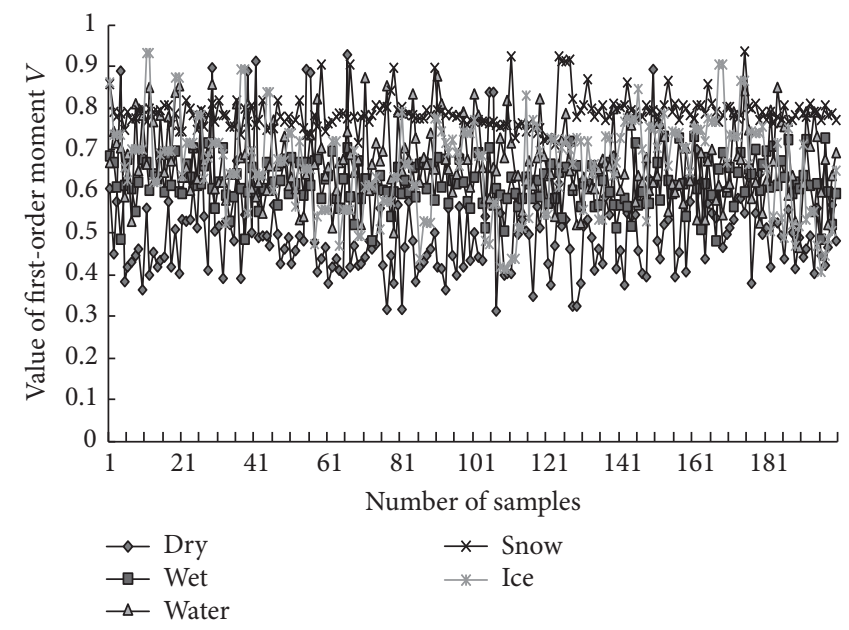

FIGURE 3: Color eigenvector: $V$ first-order moment.

transformation depends on the nonlinear transformation from the kernel function to input space. Classifier design algorithm is as follows.

Linear SVM classification function is as follows:

$$
\begin{aligned}
f(x) & =\operatorname{sgn}\left\{\left(w^{*} \cdot x\right)+b^{*}\right\} \\
& =\operatorname{sgn}\left\{\left(\sum_{\alpha=1}^{t} a_{\alpha} y_{\alpha}\left(x_{\alpha} \cdot x_{\tau}\right)\right)+b^{*}\right\}
\end{aligned}
$$

where $x$ is the input vector. $y$ is the vector type. $l$ is the number of input vectors. $w^{*}$ is the optimal weight vector. $b^{*}$ is the optimal bias. $a>0$ is the multiplier for the Lagrangian function. $x_{\alpha}$ is the support vector. $t$ is the number of support vectors.

For the nonlinear classification function, the existence of misclassified samples is allowed by introducing nonnegative slack variable $\xi_{\tau}(\tau=1,2, \ldots, l)$, and the classification hyperplane is

$$
y_{\tau}\left[\left(w \cdot x_{\tau}\right)+b\right]+\xi_{\tau} \geq 1, \quad \tau=1,2, \ldots, l .
$$






FIgURE 4: Color eigenvector: $V$ second-order moment.



FIGURE 5: Texture eigenvectors: energy.



FIgURE 6: Texture eigenvectors: entropy. 
In this case, the reciprocal of the maximum classification interval is $\min \Phi(w)=(1 / 2)\|w\|^{2}+C\left(\sum_{i=1}^{l} \xi_{\tau}\right)$, where $C>0$ is the penalty factor for SVM.

After constructing the optimal hyperplane, the most widely used Gaussian kernel function $K(x)=\exp [-g \mid x-$ $\left.\left.x_{\tau}\right|^{2}\right]$ is used $[28,29]$, and the input vector $x$ is transformed from the input space $R^{n}$ to the high-dimensional feature space $H$ with $K$ transformation,

$$
x \rightarrow K(x)=\left(K\left(x_{1}\right), K\left(x_{2}\right), \ldots, K\left(x_{l}\right)\right)^{T} .
$$

Then the input vector $x$ is replaced by the eigenvector $K(x)$, and the nonlinear optimal classification function is obtained as

$$
\begin{aligned}
f(x) & =\operatorname{sgn}(w \cdot K(x)+b) \\
& =\operatorname{sgn}\left(\sum_{\alpha=1}^{t} a_{\alpha} y_{\alpha} K\left(x_{\alpha}\right) \cdot K\left(x_{\tau}\right)+b\right) .
\end{aligned}
$$

Based on the nonlinear optimal classification function, the main idea of multiclassification can be explained as follows: Assuming that a SVM classifier is designed between every two types of samples, $k(k-l) / 2$ SVM classifiers need to be designed for $k$ samples [28]. Therefore, ten SVM classifiers are designed for the five road states. When classifying an unknown sample, each classifier evaluates and counts its type, and the most statistical result can be regarded as the type of the test sample.

4.2. Parameter Optimization of SVM. In the process of SVM classification and identification, the penalty factor $C$ and Gaussian kernel function factor $g$ have a great impact on the accuracy of training $[30,31]$. The higher $C$ can result in overlearning state, which means training set classification accuracy is high while test set classification accuracy is too low. The higher $g$ can lead to excessive support vectors and interfere with the efficiency of training and learning [31]. In order to solve the problems above, the grid searching algorithm and Particle Swarm Optimization algorithm are used to obtain the optimal parameters of $C$ and $g$ and improve the recognition efficiency and accuracy of SVM.

4.2.1. Parameters Optimization Based on Grid Searching Algorithm. Based on the grid searching algorithm, the principle of parameter optimization [30] is to make the SVM penalty factor $C$ and Gaussian kernel function factor $g$ divide the image into grids in a certain range and then traverse all the points in the grids to obtain the values. For the defined $C$ and $g$, the K-CV (cross-validation) method is used to get the training set of this group to verify the classification accuracy. Finally, the best combination of $C$ and $g$ with the highest classification accuracy of verified raining set is obtained. Where the range of $C$ is set to $\left[2^{-8}, 2^{8}\right]$, the range of $g$ is set to $\left[2^{-8}, 2^{8}\right]$.

Among them, there will be many combinations corresponding to the highest verification classification accuracy. The combination of the smallest $C$ is selected as the best one, and if the corresponding $g$ are more than one, the firstly searched combination can be selected as the best one.
4.2.2. Parameters Optimization Based on Particle Swarm Algorithm. The basic principle of Particle Swarm Optimization (PSO) [31-33] is as follows: suppose that an ethnic group $X=\left(x_{1}, x_{2}, \ldots, x_{n}\right)$ consists of $n$ particles in a $m$-dimensional search space, where the position of the $i$ th particle (the optimal solution) is $x_{i}=\left(x_{i 1}, x_{i 2}, \ldots, x_{i m}\right)^{T}$, the velocity is $V_{i}=\left(v_{1}, v_{2}, \ldots, v_{m}\right)^{T}$, and the optimal position $P_{i}=$ $\left(p_{i 1}, p_{i 2}, \ldots, p_{i m}\right)^{T}$ of the particle is denoted as pbest. The globally optimal solution $P_{g}=\left(p_{g 1}, p_{g 2}, \ldots, p_{g m}\right)^{T}$ of the ethnic group is denoted as gbest. After finding the two optimal solutions, the particle velocity and position vector are updated based on

$$
\begin{aligned}
v_{i d}(t+1)= & w \cdot v_{i d}(t)+c_{1} r_{1} \cdot\left(\text { pbest }(t)-x_{i d}(t)\right) \\
& +c_{2} r_{2} \cdot\left(\text { gbest }(t)-x_{i d}(t)\right), \\
x_{i d}(t+1)= & x_{i d}(t)+v_{i d}(t+1),
\end{aligned}
$$

where $1 \leq i \leq n$ and $1 \leq d \leq m$. $w$ is the inertia weight. $c_{1}, c_{2}$ are acceleration constants, generally set as $2 . r_{1}, r_{2}$ are random numbers ranging between 0 and $1 . t$ is the number of iterations.

Parameters optimization based on the particle swarm algorithm is as follows.

Step 1. Initialize the size and initial velocity of the particle $(C, g)$, and initialize the parameters $c_{1}, c_{2}$ and the maximum number of iterations $t$.

Step 2. The fitness value of each particle $(C, g)$ is calculated, and the classification accuracy, $R=$ number of samples correctly classified/total number of samples, trained by crossvalidation of SVM is used to evaluate the fitness value of each particle.

Step 3. The fitness value of each particle $(C, g)$ and its optimal position are compared, respectively, and the optimal value pbest is obtained. If the current value is better than pbest, pbest is set as the current value, which means the pbest location is set as the current location.

Step 4. Comparing the fitness value of each particle $(C, g)$ and the optimal value gbest of the ethnic group, if the current value is better than gbest, the subscript and fitness value of the current particle are set as the subscript and the fitness value of gbest.

Step 5. According to (12), the particle velocity and position are updated.

Step 6. When the end condition is reached, the $t$ times of iterations are completed, and the optimal value gbest is output and the best parameter $(C, g)$ can be obtained.

\section{Image Blocks Validation of Road Surface State}

Firstly, two SVM parameters optimization algorithms are used to obtain two groups of optimal training parameters 
TABLE 2: The road surface condition classification model.

\begin{tabular}{lccc}
\hline Number of training samples & Parameters optimization time consuming $(\mathrm{s})$ & Optimal $(C, g)$ & Training accuracy \\
\hline \multirow{2}{*}{2000} & Grid algorithm 2.6482 & Grid algorithm $(16,0.5)$ & Grid optimization model 90.97\% \\
& PSO algorithm 0.6848 & PSO algorithm $(12,0.46)$ & PSO optimization model 99.12\% \\
\hline
\end{tabular}

TABLE 3: Classification model performance test.

\begin{tabular}{lc}
\hline Number of test samples & Test accuracy \\
\hline 500 & Grid optimization model $88.63 \%$ \\
& PSO optimization model $97.02 \%$ \\
\hline
\end{tabular}

$(C, g)$. Then $80 \%$ of the samples in the road surface state feature database are trained based on the best training parameters $(C, g)$, and two road surface state classification models are obtained. After that, the remaining $20 \%$ of the data samples are tested to examine the performance of the two classification models. Finally, the road surface state samples in an actual environment are selected for experimental validation.

5.1. Establishment of Training Model. (1) Mark the surface state conditions: dry as $\mathrm{D}$, wet as $\mathrm{Wt}$, water as $\mathrm{Wr}$, snow as $\mathrm{S}$, and ice as I. The eigenvectors of 400 samples of each road state were extracted to form the training database.

(2) The training data is inputted into SVM classifier; the best training parameters $(C, g)$ are gotten. And then, two kinds of classification models are established.

From Table 2, it can be seen that the training accuracies of the two classification models are almost the same. However, the PSO algorithm is significantly less time-consuming and with better applicability than the grid searching algorithm.

(3) $20 \%$ of the sample data were tested by the classification model to verify the recognition performance of the two classification models. The test results are shown in Table 3.

From Table 3, it can be seen that the accuracy of the PSO model is higher than that of the grid searching algorithm, and the performance of the PSO model is better.

5.2. Image Segmentation Recognition of Actual Road Surface. Firstly, the actual road surface image is divided into blocks according to the segmentation principle. Next, the 13dimensional feature of each block is extracted. Then the road surface block feature vectors are input into two classification models mentioned above. And the state of each block will be recognized. When all the blocks are recognized, the proportion of each state will be counted.

5.2.1. Image Validation of Dry State. The recognition results of the dry road surface state under good illumination condition (from the experimental system) are shown in Figure 7 and Tables 4 and 5 .

Table 6 shows the statistic results of each road surface state.

From Table 6, it can be seen that the test ratio of dry state is $93.33 \%$ after the grid searching optimization. After the
TABLE 4: Recognition results of grid.

\begin{tabular}{lccccccccc}
\hline \multirow{2}{*}{ Column } & & \multicolumn{7}{c}{ Row } \\
& 1 & 2 & 3 & 4 & 5 & 6 & 7 & 8 & 9 \\
\hline 1 & $\mathrm{D}$ & $\mathrm{D}$ & $\mathrm{D}$ & $\mathrm{D}$ & $\mathrm{D}$ & $\mathrm{D}$ & $\mathrm{D}$ & $\mathrm{D}$ & $\mathrm{D}$ \\
2 & $\mathrm{D}$ & $\mathrm{D}$ & $\mathrm{D}$ & $\mathrm{D}$ & $\mathrm{D}$ & $\mathrm{D}$ & $\mathrm{D}$ & $\mathrm{D}$ & $\mathrm{D}$ \\
3 & $\mathrm{D}$ & $\mathrm{D}$ & $\mathrm{D}$ & $\mathrm{D}$ & $\mathrm{D}$ & $\mathrm{D}$ & $\mathrm{D}$ & $\mathrm{D}$ & $\mathrm{D}$ \\
4 & $\mathrm{D}$ & $\mathrm{D}$ & $\mathrm{D}$ & $\mathrm{D}$ & $\mathrm{D}$ & $\mathrm{D}$ & $\mathrm{D}$ & $\mathrm{D}$ & $\mathrm{D}$ \\
5 & $\mathrm{D}$ & $\mathrm{D}$ & $\mathrm{D}$ & $\mathrm{D}$ & $\mathrm{D}$ & $\mathrm{D}$ & $\mathrm{D}$ & $\mathrm{D}$ & $\mathrm{D}$ \\
\hline
\end{tabular}

TABLE 5: Recognition results of PSO.

\begin{tabular}{lccccccccc}
\hline Column & & \multicolumn{7}{c}{ Row } \\
& 1 & 2 & 3 & 4 & 5 & 6 & 7 & 8 & 9 \\
\hline 1 & $\mathrm{D}$ & $\mathrm{D}$ & $\mathrm{D}$ & $\mathrm{D}$ & $\mathrm{D}$ & $\mathrm{D}$ & $\mathrm{D}$ & $\mathrm{D}$ & $\mathrm{D}$ \\
2 & $\mathrm{Wt}$ & $\mathrm{D}$ & $\mathrm{D}$ & $\mathrm{D}$ & $\mathrm{D}$ & $\mathrm{D}$ & $\mathrm{D}$ & $\mathrm{D}$ & $\mathrm{D}$ \\
3 & $\mathrm{D}$ & $\mathrm{D}$ & $\mathrm{D}$ & $\mathrm{D}$ & $\mathrm{Wt}$ & $\mathrm{D}$ & $\mathrm{D}$ & $\mathrm{D}$ & $\mathrm{D}$ \\
4 & $\mathrm{D}$ & $\mathrm{D}$ & $\mathrm{D}$ & $\mathrm{D}$ & $\mathrm{D}$ & $\mathrm{D}$ & $\mathrm{D}$ & $\mathrm{D}$ & $\mathrm{D}$ \\
5 & $\mathrm{D}$ & $\mathrm{D}$ & $\mathrm{D}$ & $\mathrm{D}$ & $\mathrm{D}$ & $\mathrm{D}$ & $\mathrm{Wt}$ & $\mathrm{D}$ & $\mathrm{D}$ \\
\hline
\end{tabular}

optimization by PSO, the ratio of dry state is $100 \%$ and increases by $6.67 \%$.

The recognition results of dry road surface state under adverse lighting conditions (from the experimental system) are shown in Figure 8 and Tables 7 and 8.

Table 9 shows the statistic results of each road surface state.

From Table 9, it can be seen that the proportion of the test images identified as dry is $77.78 \%$ after optimization by the grid search algorithm. After the PSO optimization, the test image recognition rate is $95.56 \%$ and increases by $17.78 \%$.

5.2.2. Image Validation of Wet State. The recognition results of the wet road surface state under good illumination condition (from the surveillance system) are shown in Figure 9 and Tables 10 and 11.

Table 12 shows the statistic recognition results of each road surface state.

From Table 12, it can be seen that the proportion of the test images identified as wet is $81.25 \%$ after optimization by the grid search algorithm. After the PSO optimization, the test image recognition rate is $93.75 \%$ and increases by $12.50 \%$.

The recognition results of the wet road surface state under adverse illumination condition (from the experimental system) are shown in Figure 10 and Tables 13 and 14.

Table 15 shows the recognition results of each road surface state.

From Table 15, it can be seen that the proportion of the test images identified as wet is $80.00 \%$ after optimization by the 
TABLE 6: The dry road surface image identification results statistics.

\begin{tabular}{|c|c|c|c|c|c|c|}
\hline State & State symbol & Number of blocks & Grid search & PSO & Grid search/\% & $\mathrm{PSO} / \%$ \\
\hline Dry & $\mathrm{D}$ & & 42 & 45 & $93.33 \%$ & $100 \%$ \\
\hline Wet & $\mathrm{Wt}$ & & 3 & 0 & $6.67 \%$ & 0 \\
\hline Water & $\mathrm{Wr}$ & 45 & 0 & 0 & 0 & 0 \\
\hline Snow & S & & 0 & 0 & 0 & 0 \\
\hline Ice & I & & 0 & 0 & 0 & 0 \\
\hline
\end{tabular}



(a)



(b)

FIGURE 7: Image test results of dry road surface state under good lighting condition (from the experimental system). (a) Image of dry road surface. (b) Image blocks.



(a)



(b)

FIGURE 8: Image test results of dry road surface state under adverse lighting condition (from the experimental system). (a) Image of dry road surface state. (b) Image blocks.

TABLE 7: Recognition results of grid.

\begin{tabular}{lccccccccc}
\hline Column & & \multicolumn{8}{c}{ Row } \\
& 1 & 2 & 3 & 4 & 5 & 6 & 7 & 8 & 9 \\
\hline 1 & $\mathrm{D}$ & $\mathrm{D}$ & $\mathrm{D}$ & $\mathrm{D}$ & $\mathrm{Wt}$ & $\mathrm{D}$ & $\mathrm{D}$ & $\mathrm{D}$ & $\mathrm{D}$ \\
2 & $\mathrm{Wt}$ & $\mathrm{D}$ & $\mathrm{D}$ & $\mathrm{D}$ & $\mathrm{D}$ & $\mathrm{D}$ & $\mathrm{D}$ & $\mathrm{Wt}$ & $\mathrm{D}$ \\
3 & $\mathrm{D}$ & $\mathrm{Wt}$ & $\mathrm{D}$ & $\mathrm{D}$ & $\mathrm{Wt}$ & $\mathrm{D}$ & $\mathrm{D}$ & $\mathrm{D}$ & $\mathrm{Wt}$ \\
4 & $\mathrm{D}$ & $\mathrm{D}$ & $\mathrm{D}$ & $\mathrm{Wt}$ & $\mathrm{D}$ & $\mathrm{D}$ & $\mathrm{D}$ & $\mathrm{D}$ & $\mathrm{Wt}$ \\
5 & $\mathrm{Wt}$ & $\mathrm{D}$ & $\mathrm{D}$ & $\mathrm{D}$ & $\mathrm{D}$ & $\mathrm{D}$ & $\mathrm{Wt}$ & $\mathrm{D}$ & $\mathrm{D}$ \\
\hline
\end{tabular}

grid search algorithm. After the PSO optimization, the test image recognition rate is $93.33 \%$ and increases by $13.33 \%$.

5.2.3. Image Validation of Water State. The recognition results of the water road surface state under good illumination condition (from the mobile camera) are shown in Figure 11 and Tables 16 and 17.

Table 18 shows the recognition results of each road surface state.
TABLE 8: Recognition results of PSO.

\begin{tabular}{lccccccccc}
\hline Column & & \multicolumn{8}{c}{ Row } \\
& 1 & 2 & 3 & 4 & 5 & 6 & 7 & 8 & 9 \\
\hline 1 & $\mathrm{D}$ & $\mathrm{D}$ & $\mathrm{D}$ & $\mathrm{D}$ & $\mathrm{D}$ & $\mathrm{D}$ & $\mathrm{D}$ & $\mathrm{D}$ & $\mathrm{D}$ \\
2 & $\mathrm{D}$ & $\mathrm{D}$ & $\mathrm{D}$ & $\mathrm{D}$ & $\mathrm{D}$ & $\mathrm{D}$ & $\mathrm{D}$ & $\mathrm{D}$ & $\mathrm{D}$ \\
3 & $\mathrm{D}$ & $\mathrm{D}$ & $\mathrm{D}$ & $\mathrm{D}$ & $\mathrm{D}$ & $\mathrm{D}$ & $\mathrm{D}$ & $\mathrm{D}$ & $\mathrm{D}$ \\
4 & $\mathrm{D}$ & $\mathrm{D}$ & $\mathrm{D}$ & $\mathrm{D}$ & $\mathrm{Wt}$ & $\mathrm{D}$ & $\mathrm{D}$ & $\mathrm{D}$ & $\mathrm{D}$ \\
5 & $\mathrm{D}$ & $\mathrm{D}$ & $\mathrm{D}$ & $\mathrm{D}$ & $\mathrm{D}$ & $\mathrm{D}$ & $\mathrm{D}$ & $\mathrm{Wt}$ & $\mathrm{D}$ \\
\hline
\end{tabular}

From Table 18, it can be seen that the proportion of the test images identified as water is $78.57 \%$ after optimization by the grid search algorithm. After the PSO optimization, the test image recognition rate is $96.42 \%$ and increases by $17.85 \%$.

The recognition results of the water road surface state with reflection (from the Internet images) are shown in Figure 12 and Tables 19 and 20.

Table 21 shows the recognition results of each road surface state. 
TABLE 9: The dry road surface image identification results statistics.

\begin{tabular}{|c|c|c|c|c|c|c|}
\hline State & State symbol & Number of blocks & Grid search & PSO & Grid search $/ \%$ & $\mathrm{PSO} / \%$ \\
\hline Dry & $\mathrm{D}$ & & 35 & 43 & $77.78 \%$ & $95.56 \%$ \\
\hline Wet & $\mathrm{Wt}$ & & 10 & 2 & $22.22 \%$ & $4.44 \%$ \\
\hline Water & $\mathrm{Wr}$ & 45 & 0 & 0 & 0 & 0 \\
\hline Snow & $\mathrm{S}$ & & 0 & 0 & 0 & 0 \\
\hline Ice & I & & 0 & 0 & 0 & 0 \\
\hline
\end{tabular}

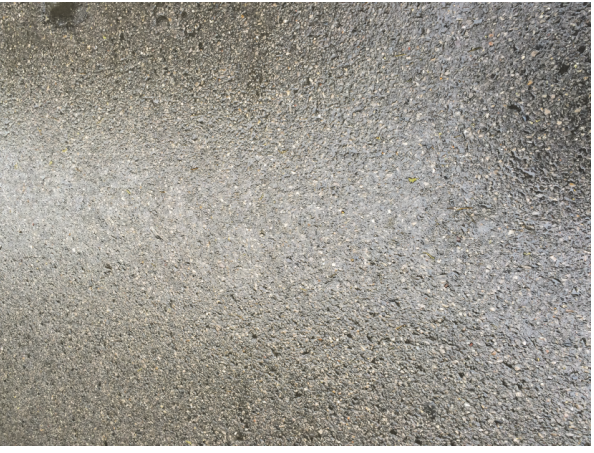

(a)



(b)

FIGURE 9: Image test results of wet road surface state under good lighting condition (from the surveillance system). (a) Image of wet road surface state. (b) Image blocks.



(a)



(b)

FIGURE 10: Image test results of wet road surface state under good lighting condition (from the experimental system). (a) Image of wet road surface state. (b) Image blocks.

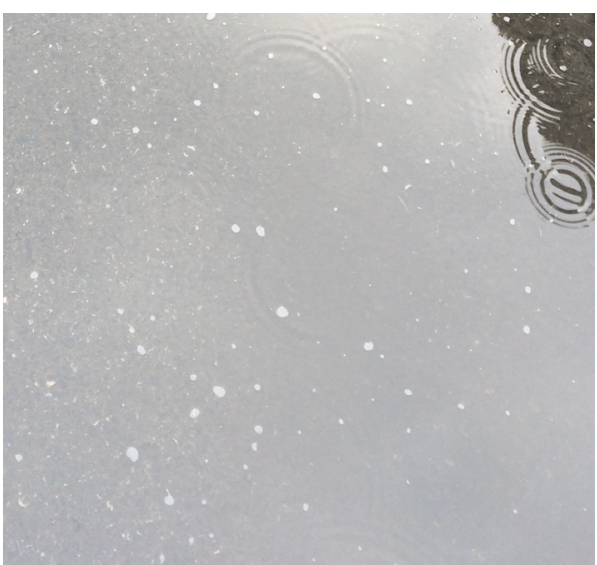

(a)



(b)

FIGURE 11: Image test results of water road surface state under good lighting condition (from the mobile camera). (a) Image of water road surface state. (b) Image blocks. 




(a)



(b)

FIGURE 12: Image test results of water road surface state with reflection (from the Internet images). (a) Image of water road surface state. (b) Image blocks.



(a)



(b)

FIGURE 13: Image test results of snow road surface (from the Internet images). (a) Image of snow road surface state. (b) Image blocks.

From Table 21, it can be seen that the proportion of the test images identified as water is $75.00 \%$ after optimization by the grid search algorithm. After the PSO is optimized, the test image recognition rate is $89.59 \%$ and increases by $14.59 \%$.

5.2.4. Image Validation of Snow State. The recognition results of the snow road surface state (from the Internet images) are shown in Figure 13 and Tables 22 and 23.

Table 24 shows the recognition results of each road surface state.

From Table 24, it can be seen that the proportion of the test images identified as water is $67.35 \%$ after optimization by
TABLE 10: Recognition results of grid.

\begin{tabular}{lcccccccc}
\hline \multirow{2}{*}{ Column } & \multicolumn{10}{c}{ Row } \\
& 1 & 2 & 3 & 4 & 5 & 6 & 7 & 8 \\
\hline 1 & $\mathrm{Wt}$ & $\mathrm{Wt}$ & $\mathrm{Wt}$ & $\mathrm{Wt}$ & $\mathrm{Wt}$ & $\mathrm{D}$ & $\mathrm{Wt}$ & $\mathrm{Wt}$ \\
2 & $\mathrm{Wt}$ & $\mathrm{Wt}$ & $\mathrm{Wt}$ & $\mathrm{Wt}$ & $\mathrm{Wt}$ & $\mathrm{D}$ & $\mathrm{Wt}$ & $\mathrm{D}$ \\
3 & $\mathrm{Wt}$ & $\mathrm{Wt}$ & $\mathrm{Wt}$ & $\mathrm{Wt}$ & $\mathrm{Wt}$ & $\mathrm{Wt}$ & $\mathrm{D}$ & $\mathrm{D}$ \\
4 & $\mathrm{Wt}$ & $\mathrm{Wt}$ & $\mathrm{Wt}$ & $\mathrm{Wt}$ & $\mathrm{Wt}$ & $\mathrm{Wt}$ & $\mathrm{Wt}$ & $\mathrm{D}$ \\
5 & $\mathrm{D}$ & $\mathrm{Wt}$ & $\mathrm{Wt}$ & $\mathrm{Wt}$ & $\mathrm{Wt}$ & $\mathrm{Wt}$ & $\mathrm{Wt}$ & $\mathrm{Wt}$ \\
6 & $\mathrm{D}$ & $\mathrm{Wt}$ & $\mathrm{Wt}$ & $\mathrm{Wt}$ & $\mathrm{Wt}$ & $\mathrm{Wt}$ & $\mathrm{Wt}$ & $\mathrm{D}$ \\
\hline
\end{tabular}

the grid search algorithm. After the PSO optimization, the test image recognition rate is $85.71 \%$ and increases by $18.36 \%$. 


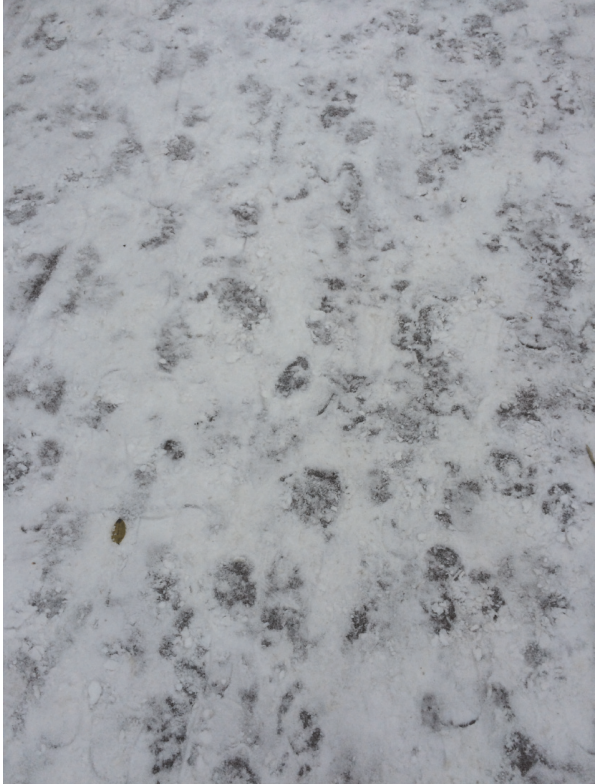

(a)

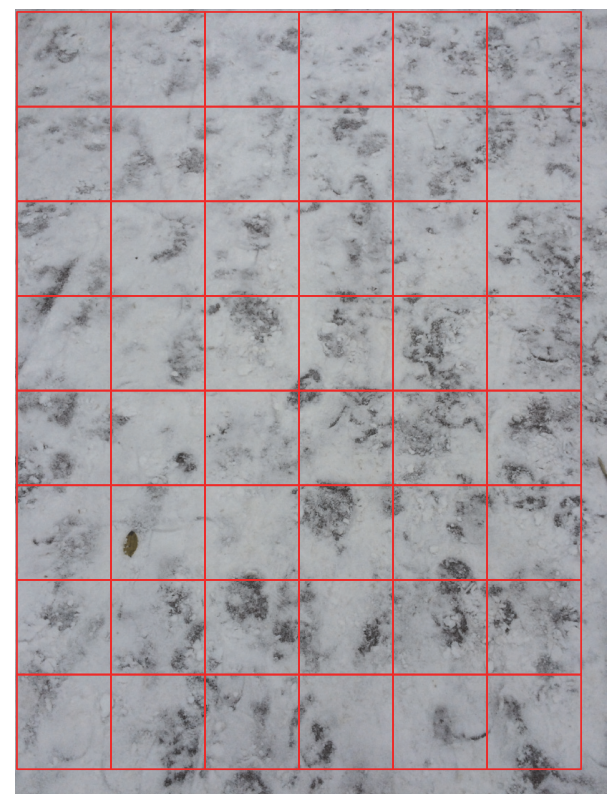

(b)

FIGURE 14: Image test results of snow road surface (from the surveillance system). (a) Image of snow road surface state. (b) Image blocks.



(a)

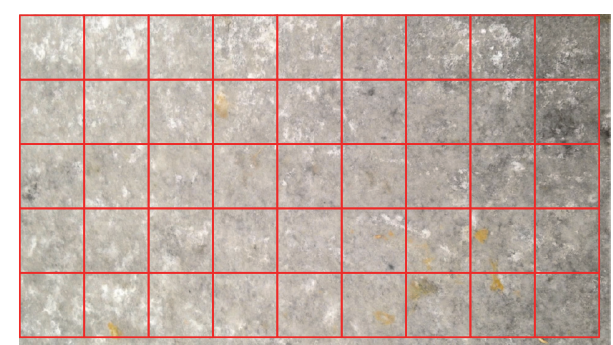

(b)

FIGURE 15: Image test results of ice road surface under good illumination condition (from the experimental system). (a) Image of ice road surface state. (b) Image blocks.

TABLE 11: Recognition results of PSO.

\begin{tabular}{lcccccccc}
\hline \multirow{2}{*}{ Column } & \multicolumn{10}{c}{ Row } \\
& 1 & 2 & 3 & 4 & 5 & 6 & 7 & 8 \\
\hline 1 & $\mathrm{Wr}$ & $\mathrm{Wt}$ & $\mathrm{Wt}$ & $\mathrm{Wt}$ & $\mathrm{Wt}$ & $\mathrm{Wt}$ & $\mathrm{Wt}$ & $\mathrm{Wt}$ \\
2 & $\mathrm{Wt}$ & $\mathrm{Wt}$ & $\mathrm{Wt}$ & $\mathrm{Wt}$ & $\mathrm{Wt}$ & $\mathrm{Wt}$ & $\mathrm{Wt}$ & $\mathrm{Wt}$ \\
3 & $\mathrm{Wt}$ & $\mathrm{Wt}$ & $\mathrm{Wt}$ & $\mathrm{Wt}$ & $\mathrm{Wt}$ & $\mathrm{Wr}$ & $\mathrm{Wt}$ & $\mathrm{Wt}$ \\
4 & $\mathrm{Wt}$ & $\mathrm{Wt}$ & $\mathrm{Wt}$ & $\mathrm{Wt}$ & $\mathrm{Wt}$ & $\mathrm{Wt}$ & $\mathrm{Wt}$ & $\mathrm{Wt}$ \\
5 & $\mathrm{Wt}$ & $\mathrm{Wt}$ & $\mathrm{Wt}$ & $\mathrm{Wr}$ & $\mathrm{Wt}$ & $\mathrm{Wt}$ & $\mathrm{Wt}$ & $\mathrm{Wt}$ \\
6 & $\mathrm{Wt}$ & $\mathrm{Wt}$ & $\mathrm{Wt}$ & $\mathrm{Wt}$ & $\mathrm{Wt}$ & $\mathrm{Wt}$ & $\mathrm{Wt}$ & $\mathrm{Wt}$ \\
\hline
\end{tabular}

The recognition results of the snow road surface state (from the surveillance system) are shown in Figure 14 and Tables 25 and 26.

Table 27 shows the recognition results of each road surface state.
From Table 27, it can be seen that the proportion of the test images identified as water is $77.55 \%$ after optimization by the grid search algorithm. After the PSO optimization, the test image recognition rate is $91.84 \%$ and increases by $14.29 \%$.

5.2.5. Image Validation of Ice State. The recognition results of the ice road surface state under good illumination condition (from the experimental system) are shown in Figure 15 and Tables 28 and 29.

Table 30 shows the recognition results of each road surface state.

From Table 30, it can be seen that the proportion of the test images identified as ice is $93.33 \%$ after optimization by the grid search algorithm. After the PSO optimization, the test image recognition rate is $97.78 \%$ and increases by $4.45 \%$.

The recognition results of the ice road surface state with snow (from the Internet image) are shown in Figure 16 and Tables 31 and 32. 
TABLE 12: The wet road surface image identification results statistics.

\begin{tabular}{|c|c|c|c|c|c|c|}
\hline $\begin{array}{l}\text { State } \\
\end{array}$ & State symbol & Number of blocks & Grid search & PSO & Grid search/\% & $\mathrm{PSO} / \%$ \\
\hline Dry & $\mathrm{D}$ & & 9 & 0 & $18.75 \%$ & 0 \\
\hline Wet & Wt & & 39 & 45 & $81.25 \%$ & $93.75 \%$ \\
\hline Water & $\mathrm{Wr}$ & 48 & 0 & 3 & 0 & $6.25 \%$ \\
\hline Snow & $\mathrm{S}$ & & 0 & 0 & 0 & 0 \\
\hline Ice & I & & 0 & 0 & 0 & 0 \\
\hline
\end{tabular}



(a)



(b)

FIGURE 16: Image test results of ice road surface with snow (from the Internet image). (a) Image of ice road surface state. (b) Image blocks.

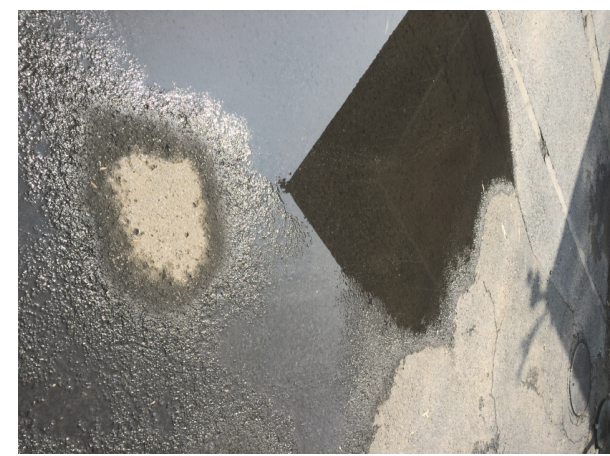

(a)



(b)

FIGURE 17: Image test results of hybrid road surface (from the mobile image). (a) Image of hybrid road surface state. (b) Image blocks.

Table 33 shows the recognition results of each road surface state.

From Table 33, it can be seen that the proportion of the test images identified as ice is $71.11 \%$ after optimization by the grid search algorithm. After the PSO optimization, the test image recognition rate is $77.78 \%$ and increases by $6.67 \%$.
5.2.6. Image Validation of Hybrid State. The recognition results of the ice, wet, and water hybrid state (from the mobile image) are shown in Figure 17 and Tables 34 and 35.

Table 36 shows the recognition results of each road surface state.

From Table 36, it can be seen that the error rate of each image block is relatively high on hybrid road condition after 
TABLE 13: Recognition results of grid.

\begin{tabular}{lccccccccc}
\hline Column & & & \multicolumn{9}{c}{ Row } & & & \\
& 1 & 2 & 3 & 4 & 5 & 6 & $\mathrm{~W}$ & 8 \\
\hline 1 & $\mathrm{Wt}$ & $\mathrm{Wt}$ & $\mathrm{Wt}$ & $\mathrm{Wt}$ & $\mathrm{Wt}$ & $\mathrm{D}$ & $\mathrm{Wt}$ & $\mathrm{Wt}$ & $\mathrm{D}$ \\
2 & $\mathrm{Wt}$ & $\mathrm{Wt}$ & $\mathrm{Wt}$ & $\mathrm{Wt}$ & $\mathrm{Wt}$ & $\mathrm{Wr}$ & $\mathrm{Wt}$ & $\mathrm{D}$ & $\mathrm{Wt}$ \\
3 & $\mathrm{Wt}$ & $\mathrm{Wt}$ & $\mathrm{D}$ & $\mathrm{Wt}$ & $\mathrm{Wt}$ & $\mathrm{D}$ & $\mathrm{Wt}$ & $\mathrm{Wt}$ & $\mathrm{Wt}$ \\
4 & $\mathrm{Wt}$ & $\mathrm{Wt}$ & $\mathrm{Wt}$ & $\mathrm{Wt}$ & $\mathrm{Wt}$ & $\mathrm{D}$ & $\mathrm{Wt}$ & $\mathrm{I}$ & $\mathrm{Wt}$ \\
5 & $\mathrm{Wt}$ & $\mathrm{Wt}$ & $\mathrm{Wt}$ & $\mathrm{Wt}$ & $\mathrm{Wt}$ & $\mathrm{D}$ & $\mathrm{Wt}$ & $\mathrm{Wt}$ & $\mathrm{Wt}$ \\
\hline
\end{tabular}

TABLE 14: Recognition results of PSO.

\begin{tabular}{lccccccccc}
\hline Column & & & \multicolumn{2}{c}{ Row } & 6 & 7 & 8 \\
\hline 1 & 1 & 2 & 3 & 4 & 5 & $\mathrm{Wt}$ & $\mathrm{Wt}$ & $\mathrm{Wt}$ & $\mathrm{Wr}$ \\
2 & $\mathrm{Wt}$ & $\mathrm{Wt}$ & $\mathrm{Wt}$ & $\mathrm{Wt}$ & $\mathrm{Wt}$ & $\mathrm{Wt}$ \\
3 & $\mathrm{Wt}$ & $\mathrm{Wt}$ & $\mathrm{Wt}$ & $\mathrm{Wt}$ & $\mathrm{Wt}$ & $\mathrm{Wt}$ & $\mathrm{Wt}$ & $\mathrm{Wt}$ \\
4 & $\mathrm{Wt}$ & $\mathrm{Wt}$ & $\mathrm{Wt}$ & $\mathrm{I}$ & $\mathrm{Wt}$ & $\mathrm{Wt}$ & $\mathrm{Wt}$ & $\mathrm{Wt}$ & $\mathrm{Wt}$ \\
5 & $\mathrm{Wt}$ & $\mathrm{Wt}$ & $\mathrm{Wt}$ & $\mathrm{Wt}$ & $\mathrm{I}$ & $\mathrm{Wt}$ & $\mathrm{Wt}$ & $\mathrm{Wt}$ & $\mathrm{Wt}$ \\
\hline & $\mathrm{Wt}$ & $\mathrm{Wt}$ & $\mathrm{Wt}$ & $\mathrm{Wt}$ & $\mathrm{Wt}$ & $\mathrm{Wt}$ & $\mathrm{Wt}$ & $\mathrm{Wt}$ & $\mathrm{Wt}$ \\
\hline
\end{tabular}

TABLE 15: The wet road surface image identification results statistics.

\begin{tabular}{|c|c|c|c|c|c|c|}
\hline State & State symbol & Number of blocks & Grid search & PSO & Grid search $/ \%$ & $\mathrm{PSO} / \%$ \\
\hline Dry & $\mathrm{D}$ & & 7 & 0 & $15.56 \%$ & 0 \\
\hline Wet & $\mathrm{Wt}$ & & 36 & 42 & $80.00 \%$ & $93.33 \%$ \\
\hline Water & $\mathrm{Wr}$ & 45 & 1 & 1 & $2.22 \%$ & $2.22 \%$ \\
\hline Snow & $\mathrm{S}$ & & 0 & 0 & 0 & 0 \\
\hline Ice & I & & 1 & 2 & $2.22 \%$ & $4.44 \%$ \\
\hline
\end{tabular}



(a)



(b)

FIGURE 18: Image test results of hybrid road surface (from the surveillance system). (a) Image of hybrid road surface state. (b) Image blocks.

the grid searching optimization. After PSO optimization, the recognition accuracy of each block of the test image is improved, and the distribution of road conditions can be given accurately.

The recognition results of the ice, wet, and water hybrid state (from the surveillance system) are shown in Figure 18 and Tables 37 and 38.

Table 39 shows the recognition results of each road surface state.

From Table 39, it can be seen that the error rate of each image block is relatively high on hybrid road condition after the grid searching optimization. After PSO optimization, the recognition accuracy of each block of the test image is improved, and the distribution of road conditions can be given accurately.

\section{Conclusions}

There are a large number of traffic accidents caused by bad weather condition or slippery road condition. Therefore, road states greatly affect the traffic safety and transport efficiency on highway. It is of great social significance to study the 
TABLE 16: Recognition results of grid.

\begin{tabular}{|c|c|c|c|c|c|c|c|}
\hline \multirow{2}{*}{ Column } & \multicolumn{7}{|c|}{ Row } \\
\hline & 1 & 2 & 3 & 4 & 5 & 6 & 7 \\
\hline 1 & $\mathrm{Wr}$ & $S$ & $\mathrm{Wr}$ & $\mathrm{Wr}$ & $\mathrm{Wr}$ & $\mathrm{Wr}$ & I \\
\hline 2 & $\mathrm{Wr}$ & $\mathrm{Wr}$ & $\mathrm{Wr}$ & $\mathrm{Wt}$ & $\mathrm{Wt}$ & $\mathrm{Wr}$ & Wr \\
\hline 3 & $\mathrm{Wr}$ & $\mathrm{Wr}$ & $\mathrm{Wt}$ & $\mathrm{Wr}$ & $\mathrm{Wr}$ & I & $\mathrm{Wr}$ \\
\hline 4 & I & $\mathrm{Wr}$ & $\mathrm{Wr}$ & $\mathrm{Wr}$ & $\mathrm{Wr}$ & $\mathrm{Wr}$ & $\mathrm{Wr}$ \\
\hline 5 & $\mathrm{Wr}$ & $\mathrm{Wr}$ & $\mathrm{Wr}$ & $\mathrm{Wr}$ & $\mathrm{Wr}$ & $\mathrm{Wr}$ & $\mathrm{Wr}$ \\
\hline 6 & $\mathrm{Wr}$ & $\mathrm{Wr}$ & $\mathrm{Wr}$ & $\mathrm{Wr}$ & $\mathrm{Wr}$ & $\mathrm{Wr}$ & $\mathrm{D}$ \\
\hline 7 & $\mathrm{Wr}$ & $S$ & $\mathrm{Wr}$ & $\mathrm{Wr}$ & $\mathrm{Wr}$ & $\mathrm{Wr}$ & I \\
\hline 8 & I & $\mathrm{Wr}$ & $\mathrm{Wr}$ & $\mathrm{Wr}$ & $\mathrm{Wr}$ & $\mathrm{Wr}$ & I \\
\hline
\end{tabular}

TABLE 17: Recognition results of PSO.

\begin{tabular}{|c|c|c|c|c|c|c|c|}
\hline \multirow{2}{*}{ Column } & \multicolumn{7}{|c|}{ Row } \\
\hline & 1 & 2 & 3 & 4 & 5 & 6 & 7 \\
\hline 1 & $\mathrm{Wr}$ & $\mathrm{Wr}$ & $\mathrm{Wr}$ & $\mathrm{Wr}$ & $\mathrm{Wr}$ & $\mathrm{Wr}$ & $\mathrm{Wr}$ \\
\hline 2 & $\mathrm{Wr}$ & $\mathrm{Wr}$ & $\mathrm{Wr}$ & $\mathrm{Wr}$ & $\mathrm{Wr}$ & $\mathrm{Wr}$ & $\mathrm{Wr}$ \\
\hline 3 & $\mathrm{Wr}$ & $\mathrm{Wr}$ & $\mathrm{Wr}$ & $\mathrm{Wr}$ & Wr & $\mathrm{Wr}$ & Wr \\
\hline 4 & $\mathrm{Wr}$ & $\mathrm{Wr}$ & $\mathrm{Wr}$ & $\mathrm{Wr}$ & $\mathrm{Wr}$ & $\mathrm{Wr}$ & Wt \\
\hline 5 & $\mathrm{Wr}$ & $\mathrm{Wr}$ & $\mathrm{Wr}$ & $\mathrm{Wr}$ & $\mathrm{Wr}$ & $\mathrm{Wr}$ & $\mathrm{Wr}$ \\
\hline 6 & $\mathrm{Wr}$ & $\mathrm{Wr}$ & $\mathrm{Wr}$ & $\mathrm{Wr}$ & $\mathrm{Wr}$ & $\mathrm{Wr}$ & Wr \\
\hline 7 & $\mathrm{Wr}$ & $\mathrm{Wr}$ & $\mathrm{Wr}$ & $\mathrm{Wr}$ & $\mathrm{Wr}$ & $\mathrm{D}$ & $\mathrm{Wr}$ \\
\hline 8 & $\mathrm{Wr}$ & $\mathrm{Wr}$ & $\mathrm{Wr}$ & $\mathrm{Wr}$ & $\mathrm{Wr}$ & $\mathrm{Wr}$ & $\mathrm{Wr}$ \\
\hline
\end{tabular}

TABLE 18: The water road surface image identification results statistics.

\begin{tabular}{|c|c|c|c|c|c|c|}
\hline State & State symbol & Number of blocks & Grid search & PSO & Grid search/\% & $\mathrm{PSO} / \%$ \\
\hline Dry & $\mathrm{D}$ & & 1 & 1 & $1.79 \%$ & $1.79 \%$ \\
\hline Wet & Wt & & 3 & 1 & $5.36 \%$ & $1.79 \%$ \\
\hline Water & $\mathrm{Wr}$ & 56 & 44 & 54 & $78.57 \%$ & $96.42 \%$ \\
\hline Snow & S & & 2 & 0 & $3.57 \%$ & 0 \\
\hline Ice & I & & 6 & 0 & $10.71 \%$ & 0 \\
\hline
\end{tabular}

TABLE 19: Recognition results of grid.

\begin{tabular}{lccccccc}
\hline Column & & \multicolumn{3}{c}{ Row } & & \\
\hline 1 & 2 & 3 & $\mathrm{Wr}$ & $\mathrm{Wr}$ & $\mathrm{Wr}$ & $\mathrm{I}$ \\
2 & $\mathrm{Wr}$ & $\mathrm{S}$ & $\mathrm{Wr}$ & $\mathrm{Wr}$ & $\mathrm{Wr}$ & $\mathrm{Wr}$ \\
3 & $\mathrm{Wr}$ & $\mathrm{Wr}$ & $\mathrm{Wr}$ & $\mathrm{Wr}$ & $\mathrm{I}$ & $\mathrm{Wr}$ \\
4 & $\mathrm{Wr}$ & $\mathrm{Wr}$ & $\mathrm{Wr}$ & $\mathrm{D}$ & $\mathrm{Wr}$ & $\mathrm{Wr}$ \\
5 & $\mathrm{I}$ & $\mathrm{Wr}$ & $\mathrm{Wr}$ & $\mathrm{Wr}$ & $\mathrm{Wr}$ & $\mathrm{Wr}$ \\
6 & $\mathrm{Wr}$ & $\mathrm{Wr}$ & $\mathrm{Wr}$ & $\mathrm{Wr}$ & $\mathrm{Wr}$ & $\mathrm{Wr}$ \\
7 & $\mathrm{Wr}$ & $\mathrm{Wr}$ & $\mathrm{Wr}$ & $\mathrm{Wr}$ & $\mathrm{Wr}$ & $\mathrm{I}$ \\
8 & $\mathrm{Wr}$ & $\mathrm{Wr}$ & $\mathrm{Wr}$ & $\mathrm{Wr}$ & $\mathrm{Wr}$ & $\mathrm{I}$ \\
\hline
\end{tabular}


TABLE 20: Recognition results of PSO.

\begin{tabular}{lcccccc}
\hline Column & & & & Row & & \\
\\
\hline 1 & 1 & 2 & 3 & $\mathrm{Wr}$ & $\mathrm{Wr}$ & $\mathrm{Wt}$ \\
2 & $\mathrm{Wr}$ & $\mathrm{Wr}$ & $\mathrm{Wr}$ & $\mathrm{Wr}$ & $\mathrm{Wt}$ \\
3 & $\mathrm{Wr}$ & $\mathrm{Wr}$ & $\mathrm{Wr}$ & $\mathrm{Wr}$ & $\mathrm{Wr}$ & $\mathrm{Wr}$ \\
4 & $\mathrm{Wr}$ & $\mathrm{Wr}$ & $\mathrm{Wr}$ & $\mathrm{Wr}$ & $\mathrm{Wr}$ & $\mathrm{Wr}$ \\
5 & $\mathrm{Wr}$ & $\mathrm{Wr}$ & $\mathrm{Wr}$ & $\mathrm{Wr}$ & $\mathrm{Wr}$ \\
6 & $\mathrm{Wr}$ & $\mathrm{Wr}$ & $\mathrm{Wr}$ & $\mathrm{Wr}$ & $\mathrm{Wr}$ \\
8 & $\mathrm{Wr}$ & $\mathrm{Wr}$ & $\mathrm{Wr}$ & $\mathrm{Wr}$ & $\mathrm{Wr}$ \\
\hline
\end{tabular}

TABLE 21: The water road surface image identification results statistics.

\begin{tabular}{|c|c|c|c|c|c|c|}
\hline State & State symbol & Number of blocks & Grid search & PSO & Grid search/\% & $\mathrm{PSO} / \%$ \\
\hline Dry & $\mathrm{D}$ & & 2 & 0 & $4.17 \%$ & 0 \\
\hline Wet & Wt & & 2 & 4 & $4.16 \%$ & $8.33 \%$ \\
\hline Water & $\mathrm{Wr}$ & 48 & 36 & 43 & $75 \%$ & $89.59 \%$ \\
\hline Snow & $\mathrm{S}$ & & 2 & 0 & $4.17 \%$ & 0 \\
\hline Ice & I & & 6 & 1 & $12.5 \%$ & $2.08 \%$ \\
\hline
\end{tabular}

TABLE 22: Recognition results of grid.

\begin{tabular}{|c|c|c|c|c|c|c|c|}
\hline \multirow{2}{*}{ Column } & \multicolumn{7}{|c|}{ Row } \\
\hline & 1 & 2 & 3 & 4 & 5 & 6 & 7 \\
\hline 1 & $\mathrm{Wr}$ & $S$ & $S$ & $S$ & $S$ & $S$ & I \\
\hline 2 & $S$ & I & S & S & S & S & S \\
\hline 3 & S & I & S & I & S & S & S \\
\hline 4 & S & I & $S$ & $S$ & I & $S$ & $S$ \\
\hline 5 & I & S & S & S & S & S & I \\
\hline 6 & I & I & S & S & S & I & $\mathrm{Wr}$ \\
\hline 7 & I & I & S & $S$ & $S$ & I & S \\
\hline
\end{tabular}

TABLE 23: Recognition results of PSO.

\begin{tabular}{|c|c|c|c|c|c|c|c|}
\hline \multirow{2}{*}{ Column } & \multicolumn{7}{|c|}{ Row } \\
\hline & 1 & 2 & 3 & 4 & 5 & 6 & 7 \\
\hline 1 & $\mathrm{Wr}$ & S & S & $S$ & S & $S$ & $\mathrm{~S}$ \\
\hline 2 & S & $S$ & $S$ & S & $S$ & S & $S$ \\
\hline 3 & $S$ & $S$ & $S$ & $S$ & $S$ & $S$ & $S$ \\
\hline 4 & $S$ & S & $S$ & S & I & $S$ & $S$ \\
\hline 5 & I & S & S & S & S & $S$ & S \\
\hline 6 & $S$ & I & $S$ & $S$ & $S$ & I & $\mathrm{Wr}$ \\
\hline 7 & $S$ & $S$ & $S$ & $S$ & $S$ & I & $S$ \\
\hline
\end{tabular}

classification of wet and slippery road condition, which can provide reference and theoretical basis for traffic control and meteorological management and ensure traffic safety.

There are many limitations in using instrument to recognize road surface conditions, and image recognition is becoming the main technology for recognizing road surface state. However, recognition under hybrid road conditions and different lighting conditions are two problems that need to be solved.

Based on SVM algorithm and image segmentation processing technology, we propose a method of video image processing technology for road surface state recognition. First 
TABLE 24: The snow road surface image identification results statistics.

\begin{tabular}{|c|c|c|c|c|c|c|}
\hline State & State symbol & Number of blocks & Grid search & $\mathrm{PSO}$ & Grid search/\% & $\mathrm{PSO} / \%$ \\
\hline Dry & $\mathrm{D}$ & & 0 & 0 & 0 & 0 \\
\hline Wet & $\mathrm{Wt}$ & & 0 & 0 & 0 & 0 \\
\hline Water & $\mathrm{Wr}$ & 49 & 2 & 2 & $4.08 \%$ & $4.08 \%$ \\
\hline Snow & S & & 33 & 42 & $67.35 \%$ & $85.71 \%$ \\
\hline Ice & I & & 14 & 5 & $28.57 \%$ & $10.20 \%$ \\
\hline
\end{tabular}

TABLE 25: Recognition results of grid.

\begin{tabular}{lllllll}
\hline Column & & & Row & & \\
& 1 & 2 & 3 & 4 & $\mathrm{~S}$ & 6 \\
\hline 1 & $\mathrm{~S}$ & $\mathrm{~S}$ & $\mathrm{~S}$ & $\mathrm{~S}$ & $\mathrm{~S}$ & $\mathrm{~S}$ \\
2 & $\mathrm{D}$ & $\mathrm{D}$ & $\mathrm{S}$ & $\mathrm{S}$ & $\mathrm{S}$ & $\mathrm{D}$ \\
3 & $\mathrm{~S}$ & $\mathrm{~S}$ & $\mathrm{~S}$ & $\mathrm{~S}$ & $\mathrm{D}$ & $\mathrm{S}$ \\
4 & $\mathrm{~S}$ & $\mathrm{~S}$ & $\mathrm{~S}$ & $\mathrm{Wr}$ & $\mathrm{S}$ & $\mathrm{S}$ \\
5 & $\mathrm{~S}$ & $\mathrm{~S}$ & $\mathrm{~S}$ & $\mathrm{~S}$ & $\mathrm{~S}$ & $\mathrm{~S}$ \\
6 & $\mathrm{~S}$ & $\mathrm{~S}$ & $\mathrm{~S}$ & $\mathrm{~S}$ & $\mathrm{Wt}$ & $\mathrm{S}$ \\
7 & $\mathrm{~S}$ & $\mathrm{~S}$ & $\mathrm{~S}$ & $\mathrm{D}$ & $\mathrm{Wt}$ & $\mathrm{S}$ \\
8 & $\mathrm{~S}$ & $\mathrm{~S}$ & $\mathrm{~S}$ & $\mathrm{D}$ & \\
\hline
\end{tabular}

TABLE 26: Recognition results of PSO.

\begin{tabular}{lllllll}
\hline Column & & & & Row & & \\
& 1 & 2 & 3 & 4 & $\mathrm{~S}$ & 6 \\
\hline 1 & $\mathrm{~S}$ & $\mathrm{~S}$ & $\mathrm{~S}$ & $\mathrm{~S}$ & $\mathrm{~S}$ & $\mathrm{~S}$ \\
2 & $\mathrm{~S}$ & $\mathrm{~S}$ & $\mathrm{~S}$ & $\mathrm{~S}$ & $\mathrm{~S}$ & $\mathrm{I}$ \\
3 & $\mathrm{~S}$ & $\mathrm{~S}$ & $\mathrm{~S}$ & $\mathrm{~S}$ & $\mathrm{~S}$ & $\mathrm{~S}$ \\
4 & $\mathrm{~S}$ & $\mathrm{~S}$ & $\mathrm{~S}$ & $\mathrm{~S}$ & $\mathrm{~S}$ & $\mathrm{~S}$ \\
5 & $\mathrm{~S}$ & $\mathrm{~S}$ & $\mathrm{~S}$ & $\mathrm{~S}$ & $\mathrm{~S}$ & $\mathrm{~S}$ \\
6 & $\mathrm{~S}$ & $\mathrm{~S}$ & $\mathrm{~S}$ & $\mathrm{~S}$ & $\mathrm{Wt}$ & $\mathrm{S}$ \\
7 & $\mathrm{~S}$ & $\mathrm{~S}$ & $\mathrm{~S}$ & $\mathrm{~S}$ & $\mathrm{~S}$ & $\mathrm{I}$ \\
8 & $\mathrm{~S}$ & $\mathrm{~S}$ & $\mathrm{~S}$ & $\mathrm{~S}$ & \\
\hline
\end{tabular}

TABLE 27: The snow road surface image identification results statistics.

\begin{tabular}{|c|c|c|c|c|c|c|}
\hline State & State symbol & Number of blocks & Grid search & PSO & Grid search/\% & $\mathrm{PSO} / \%$ \\
\hline Dry & $\mathrm{D}$ & & 7 & 0 & $14.29 \%$ & 0 \\
\hline Wet & Wt & & 2 & 1 & $4.08 \%$ & $2.04 \%$ \\
\hline Water & $\mathrm{Wr}$ & 49 & 1 & 0 & $2.04 \%$ & $0 \%$ \\
\hline Snow & $\mathrm{S}$ & & 38 & 45 & $77.55 \%$ & $91.84 \%$ \\
\hline Ice & I & & 1 & 3 & $2.04 \%$ & $6.12 \%$ \\
\hline
\end{tabular}

TABLE 28: Recognition results of grid.

\begin{tabular}{|c|c|c|c|c|c|c|c|c|c|}
\hline \multirow{2}{*}{ Column } & \multicolumn{9}{|c|}{ Row } \\
\hline & 1 & 2 & 3 & 4 & 5 & 6 & 7 & 8 & 9 \\
\hline 1 & I & I & I & I & I & I & I & $\mathrm{Wt}$ & I \\
\hline 2 & I & I & I & I & I & I & I & $\mathrm{Wt}$ & I \\
\hline 3 & I & I & I & I & I & I & I & I & I \\
\hline 4 & I & I & I & I & I & I & I & I & I \\
\hline 5 & I & I & I & I & I & $\mathrm{Wt}$ & I & I & I \\
\hline
\end{tabular}


TABLE 29: Recognition results of PSO.

\begin{tabular}{|c|c|c|c|c|c|c|c|c|c|}
\hline \multirow{2}{*}{ Column } & \multicolumn{9}{|c|}{ Row } \\
\hline & 1 & 2 & 3 & 4 & 5 & 6 & 7 & 8 & 9 \\
\hline 1 & I & I & I & I & I & I & I & I & I \\
\hline 2 & I & I & I & I & I & I & I & I & I \\
\hline 3 & I & I & I & I & I & I & I & $\mathrm{Wt}$ & I \\
\hline 4 & I & I & I & I & I & I & I & I & I \\
\hline 5 & I & I & I & I & I & I & I & I & I \\
\hline
\end{tabular}

TABLE 30: The ice road surface image identification results statistics.

\begin{tabular}{|c|c|c|c|c|c|c|}
\hline State & State symbol & Number of blocks & Grid search & PSO & Grid search/\% & $\mathrm{PSO} / \%$ \\
\hline Dry & $\mathrm{D}$ & & 0 & 0 & 0 & 0 \\
\hline Wet & $\mathrm{Wt}$ & & 3 & 1 & $6.67 \%$ & $2.22 \%$ \\
\hline Water & $\mathrm{Wr}$ & 45 & 0 & 0 & 0 & 0 \\
\hline Snow & S & & 0 & 0 & 0 & 0 \\
\hline Ice & I & & 42 & 44 & $93.33 \%$ & $97.78 \%$ \\
\hline
\end{tabular}

TABLE 31: Recognition results of grid.

\begin{tabular}{|c|c|c|c|c|c|c|}
\hline \multirow{2}{*}{ Column } & \multicolumn{6}{|c|}{ Row } \\
\hline & 1 & 2 & 3 & 4 & 5 & 6 \\
\hline 1 & $\mathrm{D}$ & I & $\mathrm{Wt}$ & I & I & I \\
\hline 2 & I & I & I & I & I & $\mathrm{D}$ \\
\hline 3 & $\mathrm{D}$ & I & I & I & I & I \\
\hline 4 & $\mathrm{Wt}$ & I & I & I & I & $\mathrm{Wt}$ \\
\hline 5 & I & Wr & $\mathrm{I}$ & I & I & I \\
\hline 6 & $\mathrm{D}$ & $\mathrm{Wt}$ & $\mathrm{D}$ & I & I & I \\
\hline 7 & I & I & I & I & I & I \\
\hline 8 & I & I & I & D & D & $\mathrm{Wt}$ \\
\hline
\end{tabular}

TABLE 32: Recognition results of PSO.

\begin{tabular}{|c|c|c|c|c|c|c|}
\hline \multirow{2}{*}{ Column } & \multicolumn{6}{|c|}{ Row } \\
\hline & 1 & 2 & 3 & 4 & 5 & 6 \\
\hline 1 & I & I & I & I & S & I \\
\hline 2 & I & I & I & $S$ & I & I \\
\hline 3 & I & I & I & $S$ & $S$ & I \\
\hline 4 & I & I & I & I & I & I \\
\hline 5 & I & I & I & I & I & $\mathrm{Wt}$ \\
\hline 6 & I & $\mathrm{Wt}$ & $\mathrm{Wt}$ & I & I & I \\
\hline 7 & I & I & I & I & $\mathrm{Wt}$ & $\mathrm{Wt}$ \\
\hline 8 & I & I & I & I & I & $\mathrm{Wt}$ \\
\hline
\end{tabular}

TABLE 33: The ice road surface image identification results statistics.

\begin{tabular}{|c|c|c|c|c|c|c|}
\hline State & State symbol & Number of blocks & Grid search & PSO & Grid search/\% & $\mathrm{PSO} / \%$ \\
\hline Dry & $\mathrm{D}$ & & 42 & 45 & $93.33 \%$ & $100 \%$ \\
\hline Wet & $\mathrm{Wt}$ & & 3 & 0 & $6.67 \%$ & 0 \\
\hline Water & $\mathrm{Wr}$ & 45 & 0 & 0 & 0 & 0 \\
\hline Snow & $\mathrm{S}$ & & 0 & 0 & 0 & 0 \\
\hline Ice & I & & 0 & 0 & 0 & 0 \\
\hline
\end{tabular}


TABLE 34: Recognition results of grid.

\begin{tabular}{lcccccccc}
\hline Column & & & & & Row & & & \\
& 1 & 2 & 3 & 4 & 5 & 6 & 7 & 8 \\
\hline 1 & $\mathrm{Wt}$ & $\mathrm{D}$ & $\mathrm{Wr}$ & $\mathrm{Wr}$ & $\mathrm{Wr}$ & $\mathrm{Wr}$ & $\mathrm{D}$ & $\mathrm{D}$ \\
2 & $\mathrm{Wt}$ & $\mathrm{Wt}$ & $\mathrm{D}$ & $\mathrm{Wr}$ & $\mathrm{Wr}$ & $\mathrm{Wr}$ & $\mathrm{D}$ & $\mathrm{Wt}$ \\
3 & $\mathrm{Wt}$ & $\mathrm{Wt}$ & $\mathrm{D}$ & $\mathrm{Wr}$ & $\mathrm{Wr}$ & $\mathrm{Wr}$ & $\mathrm{D}$ & $\mathrm{Wt}$ \\
4 & $\mathrm{Wt}$ & $\mathrm{Wt}$ & $\mathrm{Wr}$ & $\mathrm{Wt}$ & $\mathrm{Wr}$ & $\mathrm{Wt}$ & $\mathrm{D}$ & $\mathrm{Wt}$ \\
5 & $\mathrm{~S}$ & $\mathrm{~S}$ & $\mathrm{Wt}$ & $\mathrm{Wt}$ & $\mathrm{Wt}$ & $\mathrm{Wt}$ & $\mathrm{D}$ & $\mathrm{Wt}$ \\
6 & $\mathrm{D}$ & $\mathrm{Wt}$ & $\mathrm{Wr}$ & $\mathrm{Wt}$ & $\mathrm{D}$ & $\mathrm{D}$ & $\mathrm{D}$ & $\mathrm{D}$ \\
\hline
\end{tabular}

TABLE 35: Recognition results of PSO.

\begin{tabular}{lccccccccc}
\hline Column & & & & Row & & & \\
& 1 & 2 & 3 & 4 & 5 & 6 & 7 & \\
\hline 1 & $\mathrm{Wt}$ & $\mathrm{D}$ & $\mathrm{D}$ & $\mathrm{Wt}$ & $\mathrm{Wr}$ & $\mathrm{Wt}$ & $\mathrm{Wr}$ & $\mathrm{Wr}$ \\
2 & $\mathrm{D}$ & $\mathrm{D}$ & $\mathrm{D}$ & $\mathrm{Wt}$ & $\mathrm{Wr}$ & $\mathrm{Wt}$ & $\mathrm{Wr}$ & $\mathrm{Wt}$ \\
3 & $\mathrm{D}$ & $\mathrm{D}$ & $\mathrm{Wr}$ & $\mathrm{Wr}$ & $\mathrm{Wr}$ & $\mathrm{Wt}$ & $\mathrm{Wt}$ & $\mathrm{Wr}$ \\
4 & $\mathrm{D}$ & $\mathrm{D}$ & $\mathrm{Wr}$ & $\mathrm{Wr}$ & $\mathrm{Wr}$ & $\mathrm{Wt}$ & $\mathrm{D}$ & $\mathrm{Wt}$ \\
5 & $\mathrm{D}$ & $\mathrm{Wt}$ & $\mathrm{Wr}$ & $\mathrm{Wr}$ & $\mathrm{Wr}$ & $\mathrm{Wr}$ & $\mathrm{Wt}$ & $\mathrm{Wt}$ \\
6 & $\mathrm{D}$ & $\mathrm{D}$ & $\mathrm{Wr}$ & $\mathrm{Wr}$ & $\mathrm{Wr}$ & $\mathrm{Wr}$ & $\mathrm{Wr}$ & $\mathrm{Wt}$ \\
\hline
\end{tabular}

TABLE 36: The hybrid road surface image identification results statistics.

\begin{tabular}{|c|c|c|c|c|c|c|}
\hline State & State symbol & Number of blocks & Grid search & $\mathrm{PSO}$ & Grid search/\% & $\mathrm{PSO} / \%$ \\
\hline Dry & $\mathrm{D}$ & & 14 & 13 & $29.17 \%$ & $27.08 \%$ \\
\hline Wet & $\mathrm{Wt}$ & & 19 & 14 & $39.58 \%$ & $29.17 \%$ \\
\hline Water & $\mathrm{Wr}$ & 48 & 13 & 21 & $27.08 \%$ & $43.75 \%$ \\
\hline Snow & $\mathrm{S}$ & & 2 & 0 & $0.42 \%$ & 0 \\
\hline Ice & I & & 0 & 0 & 0 & 0 \\
\hline
\end{tabular}

TABLE 37: Recognition results of grid.

\begin{tabular}{lccccccccc}
\hline Column & & \multicolumn{7}{c}{ Row } \\
& 1 & 2 & 3 & 4 & 5 & 6 & 7 & 8 & 9 \\
\hline 1 & Wt & Wr & I & Wr & Wt & I & I & I & S \\
2 & Wt & I & I & I & Wt & I & I & Wt & S \\
3 & Wt & Wr & S & Wr & Wt & I & Wt & Wt & S \\
4 & Wt & Wr & I & Wr & Wt & Wt & I & Wr & Wr \\
5 & Wt & Wr & I & Wr & Wt & I & Wr & Wr & S \\
\hline
\end{tabular}

TABLE 38: Recognition results of PSO.

\begin{tabular}{lccccccccc}
\hline \multirow{2}{*}{ Column } & \multicolumn{7}{c}{ Row } \\
& 1 & 2 & 3 & 4 & 5 & 6 & 7 & 8 & 9 \\
\hline 1 & I & I & I & I & I & I & Wt & Wt & I \\
2 & I & Wt & Wt & I & I & I & I & I & I \\
3 & S & S & S & I & I & I & I & I & I \\
4 & S & I & S & I & I & I & Wt & I & I \\
5 & S & I & I & I & I & I & S & I & Wt \\
\hline
\end{tabular}

of all, according to the segmentation principle, the road surface samples are divided into blocks and the road surface state sample database is constructed. Then, 9-dimensional color eigenvectors and 4-dimensional texture eigenvectors are extracted to form a 13-dimensional eigenvectors database which can describe the road surface state. After that, the SVM classifier is trained by using grid searching optimization and PSO optimization to obtain the road surface state classification model. And then, the performances of two classification models are tested. Finally, a road surface state recognition program was developed to test the actual road surface state images in a variety of environments.

The test results show that (1) the establishment of a perfect sample database is the basis for accurate recognition of road surface state. The quality and purity of the sample database can be ensured by dealing with single state image blocks. (2) Each feature value of the five states has overlapping parts, while 13-dimensional eigenvectors can satisfy the need of state recognition accurately. (3) After the SVM parameter optimization, the performance of road state classification model is superior, in which the performance of the PSO algorithm is better than that of the grid searching optimization algorithm, and the accuracy of state recognition is improved. (4) Image segmentation method can be used to obtain the distribution of road surface state, which solves the problem of hybrid road surface state and road surface under different 
TABLE 39: The hybrid road surface image identification results statistics.

\begin{tabular}{|c|c|c|c|c|c|c|}
\hline State & State symbol & Number of blocks & Grid search & $\mathrm{PSO}$ & Grid search/\% & $\mathrm{PSO} / \%$ \\
\hline Dry & $\mathrm{D}$ & & 0 & 0 & 0 & 0 \\
\hline Wet & $\mathrm{Wt}$ & & 14 & 6 & $31.11 \%$ & $13.33 \%$ \\
\hline Water & $\mathrm{Wr}$ & 45 & 12 & 0 & $26.67 \%$ & 0 \\
\hline Snow & $S$ & & 5 & 7 & $11.11 \%$ & $15.56 \%$ \\
\hline Ice & I & & 14 & 32 & $31.11 \%$ & 71.11\% \\
\hline
\end{tabular}

light conditions. The recognition accuracy of single state is above $90 \%$, and the recognition accuracy of hybrid state is more than $85 \%$.

\section{Conflicts of Interest}

The authors declare that there are no conflicts of interest regarding the publication of this article.

\section{Authors' Contributions}

Jiandong Zhao and Hongqiang Wu presented the algorithms, analyzed the data, and cowrote the paper; Liangliang Chen installed the experimental system and performed the experiments.

\section{Acknowledgments}

This work is supported by the Fundamental Research Funds for the Central Universities (2016JBM053).

\section{References}

[1] X. Sun, Research on Risk Coupling of Highway Traffic Safety Based on Catastrophe Theory, Beijing Jiaotong University, Beijing, 2015.

[2] Z. J. Bao, Y. Y. Tang, and C. C. Li, Highway Traffic Safety and Weather Effects, China Communications Press, Beijing, China, 2008.

[3] L. Cai, D. C. Zhang, B. Li, L. D. Gao, and L. Wang, "Traffic meteorological embedded road conditions detector test method research," Road Traffic and Safety, vol. 14, no. 6, pp. 55-59, 2014.

[4] D. Gailius and S. Jacenas, "Ice detection on a road by analyzing tire to road friction ultrasonic noise," Ultragarsas, vol. 62, no. 2, pp. 17-20, 2007.

[5] Z. Qi, B. Wang, X. Pei, and G. Ma, "A method of road surface identification based on road characteristics and the features of antilock braking adjustment," Automotive Engineering, vol. 36, no. 3, pp. 310-315, 2014.

[6] J. Alonso, J. M. López, I. Pavón et al., "On-board wet road surface identification using tyre/road noise and support vector machines," Applied Acoustics, vol. 76, no. 1, pp. 407-415, 2014.

[7] W. Wang, Q. Wu, X. Chu, and Y. Wu, "Discussion to information acquisition technology and safety identification method of traffic environment," in Proceedings of the 2008 PacificAsia Workshop on Computational Intelligence and Industrial Application, PACIIA '08, pp. 874-878, December 2008.

[8] K. Andreas and B. Wilco, "Winter road condition recognition using video image classification," Journal of the Transportation Research Record, vol. 1627, no. 1, pp. 29-33, 1998.
[9] S. Anis, K. Majdi, and B. Jacques, "Characterization of road micro texture by means of image analysis," Laboratoire Signal, Image at Communications, vol. 264, no. 5, pp. 464-468, 2008.

[10] Y. Chen, "Image analysis applied to black ice detection," in Applications of Artificial Intelligence IX, Proceedings of SPIE, pp. 551-562, April 1991.

[11] K. Ueda, I. Horiba, and K. ledaga, "A detecting method of wet condition on road using image processing," Information Processing Society of Japan, vol. 35, no. 6, pp. 1072-1080, 1994.

[12] S. Yoda, H. Okabe, J. Takagi, and T. Yamashita, "Road surface recognition sensor using an optical spatial filter," in Proceedings of the IEEE Conference on Intelligent Transportation System, pp. 253-257, 1997.

[13] I. Yamamoto, M. Kawana, and I. Yamazaki, "The application of visible image road surface sensors to winter road management," in Proceedings of the IEEE Conference on Society of Automotive Engineers of Japan, pp. 1-11, 2005.

[14] Y. Muneo, U. Koji, H. Isao, Y. Shin, and T. Sadayuk, "Detection of wet-road conditions from images captured by a vehiclemounted camera," Journal of Robotics and Mechatronics, vol. 17, no. 3, pp. 269-276, 2005.

[15] I. Becchi, E. Caporali, F. Castelli, and C. Lorenzini, "Field analysis of the water film dynamics on a road pavement," Physics and Chemistry of the Earth, Part C: Solar, Terrestrial and Planetary Science, vol. 26, no. 10-12, pp. 717-722, 2001.

[16] H. Fukui, J. Takagi, Y. Murata, and M. Takeuchi, "Image processing method to detect road surface condition using optical spatial frequency," in Proceedings of the 1997 IEEE Conference on Intelligent Transportation Systems, ITSC, pp. 1005-1009, November 1997.

[17] H. Li, Y. H. Feng, and J. Lin, "Study on road surface condition identification based on BP network improved," Microcomputer Information, vol. 26, no. 2, pp. 3-4, 2010.

[18] X. Y. Liu and Q. D. Huang, "Study on classifier of wetroad images based on SVM," Journal of Wuhan University of Technology (Transportation Science and Engineering), vol. 35, no. 4, pp. 784-787, 2011.

[19] J. Wan, K. Zhao, and W. F. Wang, "Classification of slippery road images based on high-dimensional features and RBF Neural Network," Journal of Transportation Information and Safety, vol. 31, no. 2, pp. 32-35, 2013.

[20] S. B. Zhang, S. H. Quan, and Y. Shi, "Study on image retrieval algorithm based on color moment," Computer Engineering, vol. 40, no. 6, pp. 252-255, 2014.

[21] S. R. Shinde, S. Sabale, and S. Kulkarni, "Experiments on content based image classification using Color feature extraction," in Proceedings of the 2015 International Conference on Communication, Information and Computing Technology, ICCICT '15, January 2015. 
[22] A. M. Bhave, M. Wanjari, and G. Sawarkar, "IRetrieval: image retrieval based on color feature and texture feature," International Journal of Advanced Research in Computer Science, 2014.

[23] R. M. Haralick, K. Shanmugam, and I. Dinstein, "Textural features for image classification," IEEE Transactions on Systems, Man and Cybernetics, vol. 3, no. 6, pp. 610-621, 1973.

[24] P. Mohanaiah, P. Sathyanarayana, and L. Gurukumar, "Image texture feature extraction using GLCM approach," International Journal of Scientific and Research Publications, 2013.

[25] E. G. Karakasis, G. A. Papakostas, D. E. Koulouriotis, and V. D. Tourassis, "A unified methodology for computing accurate quaternion color moments and moment invariants," IEEE Transactions on Image Processing, vol. 23, no. 2, pp. 596-611, 2014.

[26] M. Benco, R. Hudec, and P. Kamencay, "An advanced approach to extraction of colour texture features based on GLCM," International Journal of Advanced Robotic Systems, vol. 11, no. 1, pp. 129-163, 2014.

[27] R. Quevedo, E. Valencia, J. M. Bastías, and S. Cárdenas, "Description of the enzymatic browning in avocado slice using GLCM image texture," Lecture Notes in Computer Science, vol. 8334, pp. 93-101, 2014.

[28] A. Gain and D. Roy, "A novel algorithm for object detection in low contrast image and recognition by SVM," International Journal of Science and Research, vol. 4, no. 10, 2015.

[29] P. Lameski, E. Zdravevski, and R. Mingov, "SVM parameter tuning with grid search and its impact on reduction of model over-fitting," International Joint Conference on Rough Sets, vol. 9437, pp. 464-474, 2015.

[30] O. Devos, C. Ruckebusch, A. Durand, L. Duponchel, and J.-P. Huvenne, "Support vector machines (SVM) in near infrared (NIR) spectroscopy: focus on parameters optimization and model interpretation," Chemometrics and Intelligent Laboratory Systems, vol. 96, no. 1, pp. 27-33, 2009.

[31] J. Caliaperumal, S. Wowk, and S. Jones, "Simultaneous feature selection and LS-SVM parameters optimization algorithm based on PSO," in Proceedings of the 2009 WRI World Congress on Computer Science and Information Engineering, CSIE '09, vol. 5, pp. 723-727, April 2009.

[32] A. Ozbeyaz, M. I. Gursoy, and R. Coban, "Regularization and kernel parameters optimization based on PSO algorithm in EEG signals classification with SVM," in Proceedings of the 2011 IEEE 19th Signal Processing and Communications Applications Conference (SIU), pp. 399-402, Antalya, Turkey, April 2011.

[33] C. López-Franco, L. Villavicencio, N. Arana-Daniel, and A. Y. Alanis, "Image classification using PSO-SVM and an RGB-D sensor," Mathematical Problems in Engineering, vol. 2014, Article ID 695910, 17 pages, 2014. 




\section{Enfincering}




The Scientific World Journal



\section{Hindawi}

Submit your manuscripts at

https://www.hindawi.com


\section{Rotating}

Machinery




Distributed

Journal of

Control Science

and Engineering


Sensor Networks 